\title{
Low-Voltage Ride-Through Techniques for DFIG-Based Wind Turbines: State-of-the-Art Review and Future Trends
}

\author{
Marwa Ezzat, Mohamed Benbouzid, S.M. Muyeen and Lennart Harnefors
}

\begin{abstract}
This paper deals with low-voltage ride-through (LVRT) capability of wind turbines (WTs) and in particular those driven by a doubly-fed induction generator (DFIG). This is one of the biggest challenges facing massive deployment of wind farms. With increasing penetration of WTs in the grid, grid connection codes in most countries require that WTs should remain connected to the grid to maintain the reliability during and after a short-term fault. This results in LVRT with only $15 \%$ remaining voltage at the point of common coupling (PCC), possibly even less. In addition, it is required for WTs to contribute to system stability during and after fault clearance. To fulfill the LVRT requirement for DFIG-based WTs, there are two problems to be addressed, namely, rotor inrush current that may exceed the converter limit and the dc-link overvoltage. Further, it is required to limit the DFIG transient response oscillations during the voltage sag to increase the gear lifetime and generator reliability.

There is a rich literature addressing countermeasures for LVRT capability enhancement in DFIGs; this paper is therefore intended as a comprehensive state-of-the-art review of solutions to the LVRT issue. Moreover, attempts are made to highlight future issues so as to index some emerging solutions.
\end{abstract}

Index Terms-Wind turbine, doubly-fed induction generator, low voltage ride-through, grid requirements.

\section{INTRODUCTION}

The attention soars towards the sustainable energy sources, in particular the wind energy. This one is considered as the most important and most promising renewable energy sources in terms of development. As wind-power capacity has increased, so has the need for wind power plants to become more active participants in maintaining the operability and power quality of the power grid. As a result, it becomes necessary to require wind power plants to behave as much as possible as conventional power plants [1].

M. Ezzat is with Mansoura University, Department of Electrical Engineering, Mansoura, Egypt (email: mm_ezzat@mans.edu.eg).

M.E.H Benbouzid is with the University of Brest, EA 4325 LBMS, Rue de Kergoat, CS 93837, 29238 Brest, France (e-mail: Mohamed.Benbouzid@univbrest.fr).

S.M. Muyeen is with the Electrical Engineering Department, Petroleum Institute, Abu Dhabi 2533, United Arab Emirates (e-mail: s.m.muyeen@pi.ac.ae).

L. Harnefors is with $\mathrm{ABB} \mathrm{AB}$, Corporate Research Västerås, Sweden (email: lennart.harnefors@se.abb.com).
An increasing number of power system operators have implemented technical standards known as grid codes that wind turbines must meet when connecting to the grid [2-5]. The grid code technical specifications are divided into static and dynamic requirements. The static requirements discuss the steady state behavior and the power flow at the connection point to the transmission grid. While the dynamic requirements concern the desired wind turbine generator behavior during fault and disturbance periods. Generally, these requirements cover many topics such as, voltage operating range, power factor regulation, frequency operating range, grid support capability, and low fault ride-through capability. Indeed, grid codes dictate Fault Ride-Through (FRT) requirements. Low-Voltage Ride-Through (LVRT) capability is considered to be the biggest challenge in wind turbines design and manufacturing technology [6]. LVRT requires wind turbines to remain connected to the grid in presence of grid voltage sags.

The Doubly-Fed Induction Generator (DFIG) is one of the most frequently deployed large grid-connected wind turbines. Indeed, when compared with the full-scale power converter WT concept, the DFIG offers some advantages, such as reduced inverter and output filter costs due to low rotor- and grid-side power conversion ratings $(25 \%-30 \%)$ [7]. However, DFIG-based WTs are very sensitive to grid disturbances, especially to voltage dips [8].

The present paper is organized as follows. Section II shortly describes grid code requirements. The problem statement is explained in section III. Section IV mainly discusses the countermeasures for LVRT capability enhancement in DFIGs.

\section{GRID-CODE REQUIREMENTS}

Grid-code requirements typically refer to large wind farms connected to the transmission system, rather than smaller stations connected to the distribution network. These new grid codes stipulate that wind farms should contribute to power system control (frequency and also voltage), much as the conventional power stations, and emphasize wind farm behavior in case of abnormal operating conditions of the network (such as in case of voltage dips). The most common requirements include FRT capability, extended system voltage and frequency variation limits, active power regulation, and frequency control, as well as reactive power/power factor and voltage regulation capabilities [9-12]. 
The typical grid codes main requirements are given below.

\section{A. Active Power}

Wind power plants must have the ability to regulate their active power output to ensure a stable frequency in the system and to prevent lines overloading. Maximum ramp rates are imposed on the wind turbine.

\section{B. Reactive Power}

Wind power plants should have a reactive power capability to maintain the reactive power balance and the power factor in the desired range (typically between 0.9 (lag) to 0.98(lead)).

\section{Frequency Operating Range}

Wind power plants are required to run continuously within typical grid frequency variations between $49.5 \mathrm{~Hz}$ and 50.5 $\mathrm{Hz}$.

\section{Low Voltage Ride-Through}

In the event of a voltage drop, turbines are required to remain connected for specific time duration before being allowed to disconnect. This requirement is to ensure that there is no generation loss for normally cleared faults. Disconnecting a wind generator too quickly could have a negative impact on the grid, particularly with large wind farms.

Grid codes invariably require that large wind farms must withstand voltage sags down to a certain percentage of the nominal voltage and for a specified duration. Such constraints are known as FRT or LVRT requirements. They are described by a voltage versus time characteristic, denoting the minimum required immunity of the wind power station to the system voltage sags (Figs.1 and 2) [13].

\section{PROBLEM STATEMENT}

As previously mentioned, DFIGs suffer from griddisturbance sensitivity. The reason behind this problem is related to the fact that the DFIG stator is directly connected to the grid, as shown in Fig. 3 [14].

During grid faults, one or more of the phase voltages at the PCC may suddenly drop to close to zero. This results in large stator current transients, leading to high currents flowing through the converters due to the magnetic coupling between stator and rotor windings [15]. As the converter ratings are defined according to the desired variable speed range under normal grid voltage conditions, it may not be possible to synthesize the control action required to control the rotor currents during transients. Indeed, when the rotor-side voltage or current reaches the power converter limit, DFIG control is lost and protected against the converter thermal breakdown. Even if the DFIG is subjected to small stator voltage imbalance, with the converter operating inside its limits, the stator current may be highly unbalanced, leading to torque pulsations that result in acoustic noise and, at high levels, may destroy the rotor shaft, gearbox, and blade assembly [16].

Dedicated countermeasures, in terms of protection and control, are therefore needed.

\section{DFIG-BASED WT LVRT TECHNOLOGIES REVIEW}

Several countermeasures discussed in the literatures have addressed the LVRT capability enhancement in DFIGs.

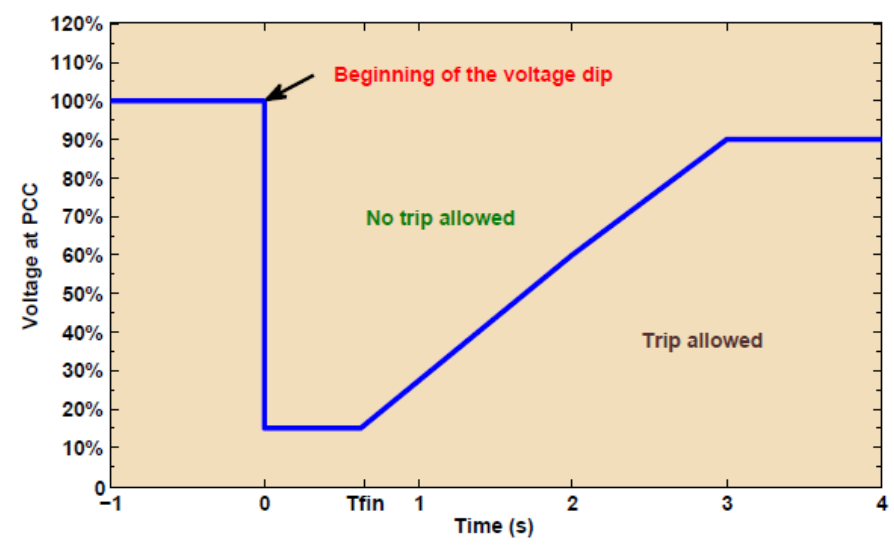

Fig. 1. Typical LVRT curve.

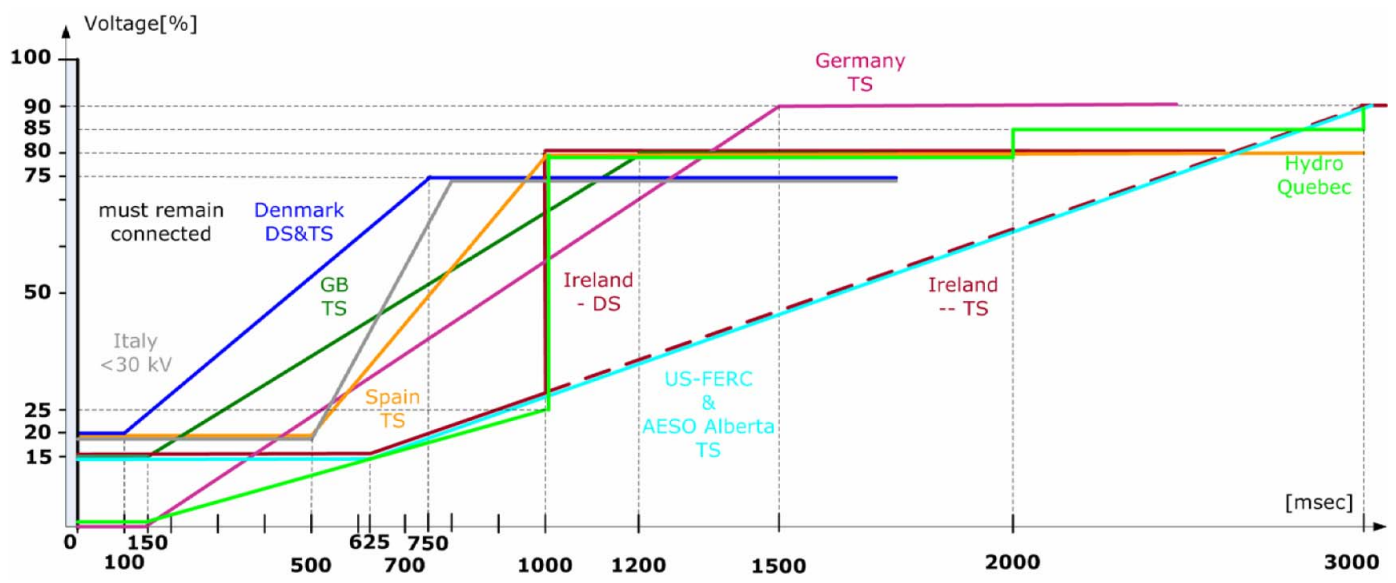

Fig. 2. LVRT requirements for different countries [13]. 


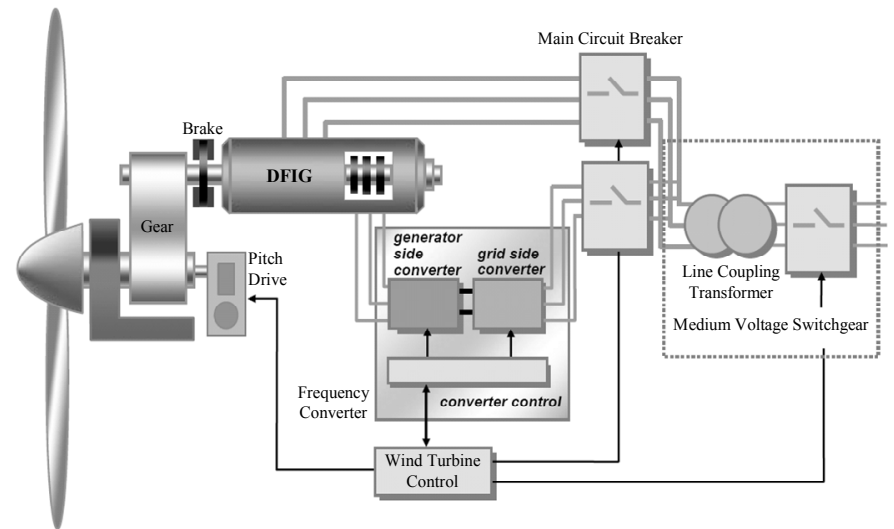

Fig. 3. Schematic diagram of a DFIG-based wind turbine.

These approaches can be divided into two main categories: 1) Passive Methods using additional equipments such as blade pitch angle control, crowbar methods; energy capacitor system (ECS) or DC capacitor sizing, and energy storage system (ESS) or DC bus energy storage circuit (Fig. 4); and 2) Active Methods using appropriate converter control.

\section{A. Passive Methods}

1) Blade pitch angle control. Pitch control achieves power reduction by rotating each blade to reduce their attack angle. In comparison with passive stall, pitch control provides an increased energy capture at rated wind speed and above. Constant-speed wind turbines can be equipped with pitch drives which quickly increase the pitch angle when rotor acceleration is detected. This reduces the mechanical power and consequently limits the rotor speed and the reactive power consumption after the fault [17].

2) Crowbar methods. The classical solution to fulfill LVRT requirements is the use of the rotor crowbar method as shown in Fig. 5 [18-19]. It is the mainstream scheme adopted by manufacturers to ride through grid faults. Although the crowbar is a cost-effective method able to protect the generator and the converter during the faults, it has some disadvantages that cannot be overlooked. Its major disadvantage is that, the DFIG loses its controllability once the crowbar is triggered, due to the rotor-side converter deactivating. In such a situation, the DFIG absorbs a large amount of reactive power from the grid, leading to further grid voltage degradation. In addition, the crowbar resistance should also be carefully calculated in order to provide sufficient damping and minimum energy consumption. Considering these drawbacks, another crowbar arrangement was proposed [20], where the crowbar is in series with the stator windings as shown in Fig. 6. Nevertheless, there are conduction losses of the bidirectional switches during normal operation. Therefore, special consideration should be taken when designing the power electronics, for minimizing these losses.

3) Energy capacitor system. The DC capacitor sizing method resembles to some extent to crowbar configuration, except that this method protects the IGBTs from overvoltage and can dissipate energy. However, this has no effect on the rotor currents [21].

4) Energy storage system. ESS-based methods have the ability to control the generator during the fault.

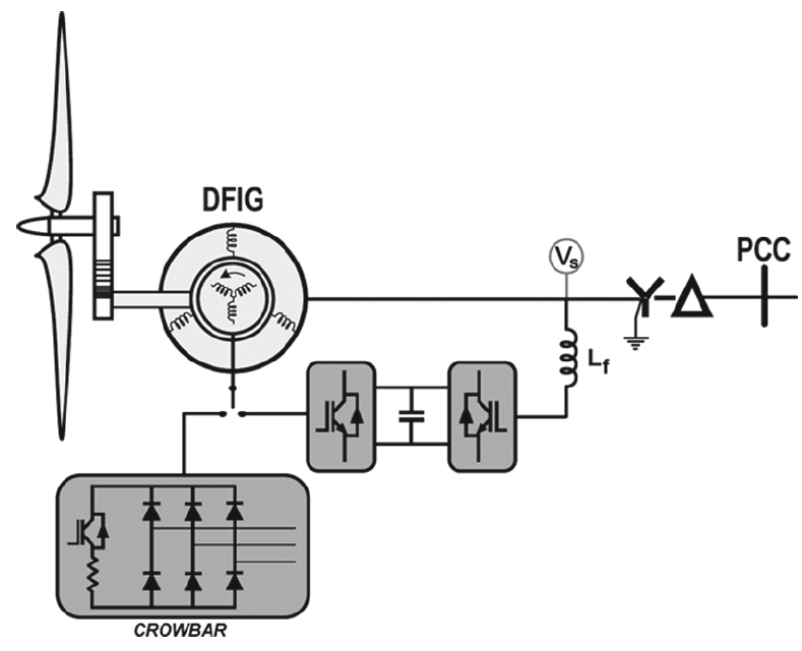

Fig. 5. Classical rotor-side crowbar [19].

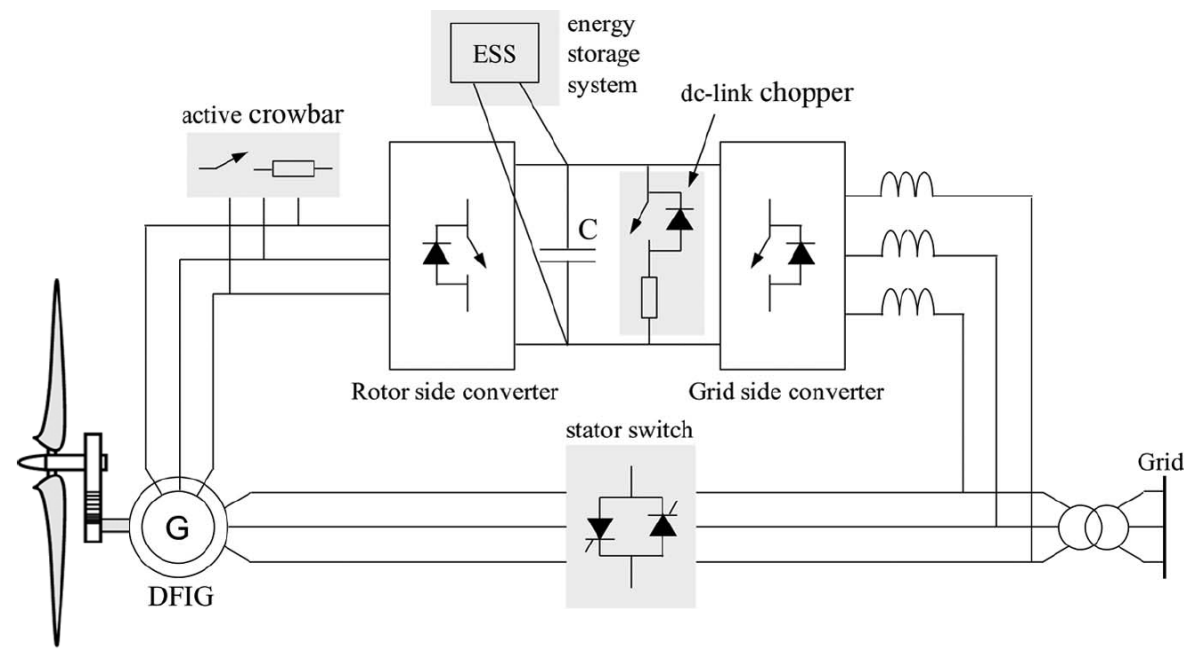

Fig. 4. Rotor and converter protection devices. 


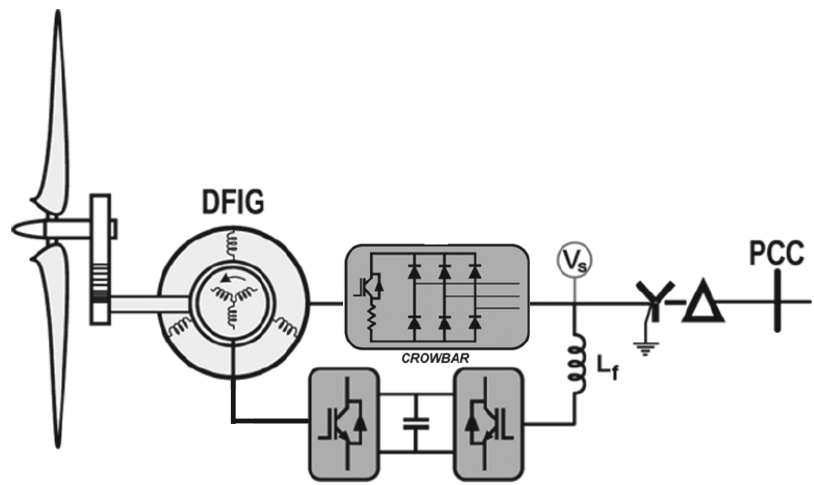

Fig. 6. Stator-side crowbar.

However, the rotor-side converter must be sized accordingly in order to allow fault currents to flow through the DFIG rotor circuit as illustrated by Fig. 7. Moreover, additional energy storage devices are required leading to the system increased cost and complexity [22-25].

\section{B. Actives Methods}

In this context, it has been also proposed combination between hardware modifications (e.g., crowbar) and control strategies [26-27]. The authors propose a feed-forward transient current control scheme for the rotor side converter (RSC) of a DFIG with crowbar protection. By injecting additional feed-forward transient compensation terms into the outputs of a conventional (PI) RSC current controller, the RSC AC-side output voltage will be aligned with the transientinduced voltage resulting in minimum transient rotor current and minimum occurrence of crowbar interruptions. Compared to the conventional controller, little additional computation effort is needed in this new control scheme.

Another solution is proposed by [28]. The proposed configuration uses a parallel grid side rectifier (PGSR) with a series grid side converter (SGSC) as shown in Fig. 8. The combination of these two converters enables unencumbered power processing and robust voltage disturbance ride through. It was reported that the generator side converter recovers the rotor slip into the DC link as in a traditional DFIG.

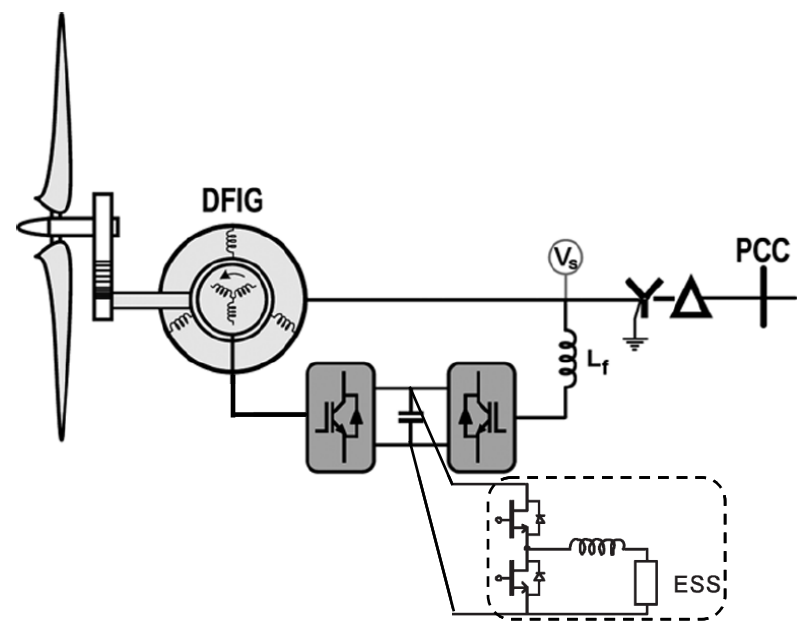

Fig. 7. DFIG-based WT equipped with ESS.

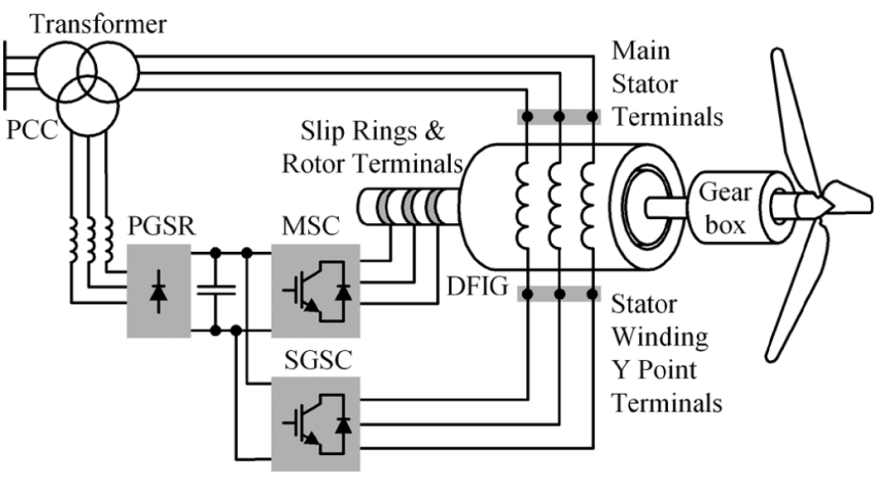

Fig. 8. DFIG-based WT with PGSR and SGSC [28].

However, a series-connected grid side converter is used to inject the DC link power into the grid. Although this approach allows power flow control over a typical operating range above and below synchronous speed, the DFIG suffers at subsynchronous speeds. Therefore, a parallel-connected passive rectifier rated at a small fraction of the total power is used to restore the overall system maximal utilization.

Yet, all these solutions require additional devices. This leads to extra costs and increase the system complexity. From this point of view, it would be better to eliminate these devices. With these considerations, the implementation of classical flux-oriented vector control techniques (PI controllers) has been proven to work well for the accomplishment of the initial grid code requirements [29-30]. But, this kind of control could be easily saturated when dealing with substantial sag. Moreover, it is sensitive to the generator parameters and other phenomena such as disturbances and unmodeled dynamics [31-32].

Recent network operator requirements seem to lead to more robust control techniques [9]. Indeed, the above classical control techniques main drawback is their linear nature that lacks robustness when facing a worst-case operation scenario. In this context, it should be mentioned that there are few publication addressing the nonlinear control of DFIGs during grid faults [15], [33-36].

For instance, the work presented in [16] proposes a robust nonlinear controller based on the sliding mode. This controller is designed in a stationary reference frame. The behavior of this controller is investigated and tested under unbalanced voltage dip conditions. Some experimental results are given to confirm the proposed controller efficiency. The main limitation of this solution is the chattering problem.

In [34], an LVRT scheme for a PMSG-based WT is proposed. Based on the feedback linearization theory, the DClink voltage is controlled by the generator rotor-side converter instead of the grid-side converter which is usually used.

In [35], it is suggested a susceptance control strategy which can cater for the reactive power requirement. The susceptance is adjusted through a robust feedback controller included in the terminal voltage driven automatic excitation control circuit. The fixed parameter robust controller design was carried out in frequency domain using multiplicative uncertainty modeling and $\mathrm{H}_{\infty}$ norms. The robust controller has demonstrated capability to ride though low voltage conditions. 
However, this LVRT approach still needs experimental validation.

Finally, in [36-37], another control strategy using a highorder sliding mode (HOSM) technique is proposed (Fig. 9). Such a control scheme, contrary to the traditional PI controller, presents attractive features such as chattering-free behavior (no extra mechanical stress), finite reaching time, and robustness with respect to external disturbances (grid) and unmodeled dynamics (DFIG and WT). Preliminary results in case of frequency variation and voltage unbalance sags show promising successful ride-through performances [36].

\section{TECHNOLOGY SOLUTIONS TO THE LVRT ISSUE}

Newer turbine models from industry leaders come with LVRT as integral. Full converter wind turbines have the greatest ability to meet the most restrictive grid codes (although many products currently on the market do not) [38]. These also offer the highest levels of flexibility in generator technology, and are gaining ground in the marketplace. For example, ENERCON has a full converter turbine, as does VESTAS in its $V 1123 \mathrm{MW}$ model.

However, turbines based upon the DFIG concept, which use relatively small converters, are also in almost all cases unable to meet rising LVRT and reactive power requirements. This is the dominant technology in terms of existing capacity [39].

Technology suppliers have therefore been working with transmission grid operators and turbine manufacturers to introduce technological solutions to the LVRT issue. Companies such as ELSPEC [40] have introduced systems to inject reactive power, while AMSC [41] and ZIGOR [42] have developed uninterruptible supply solutions. And W2PS [43] has developed a solution that works as a parallel solution, connected in series, protecting the wind turbine.

\section{CONCLUSION}

LVRT is found to be one of the biggest challenge facing wind turbine farms massive deployment; in particular those using DFIGs.

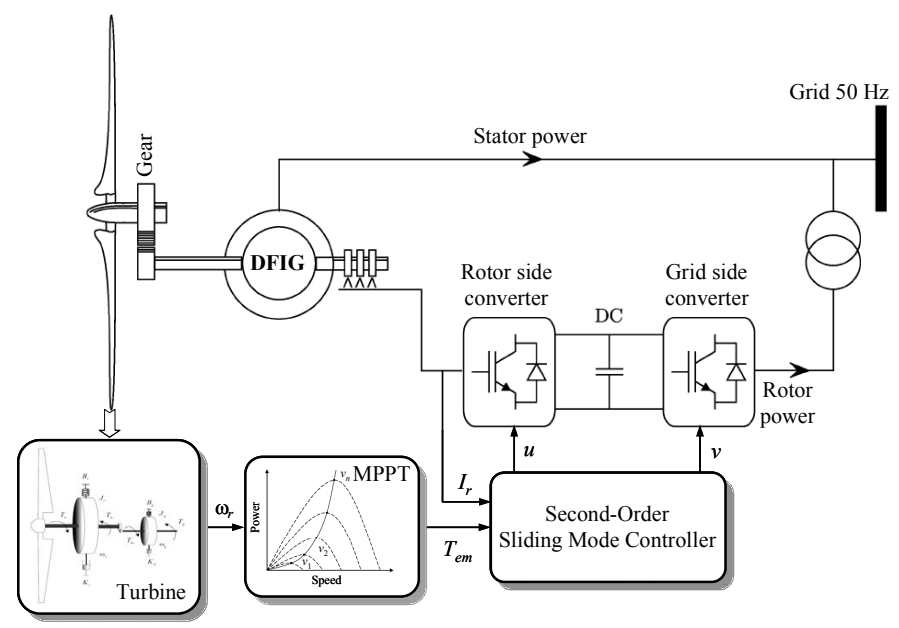

Fig. 9. DFIG-based WT LVRT using HOSM [36].
This type of generator is unfortunately sensitive to grid disturbance, in particular voltage sags. To overcome this sensitivity, several hardware and control strategies have been proposed. These strategies have been examined and advantages and disadvantages of each one have been discussed. The use of additional hardware can be avoided if the rotor-side converter is able to counter the grid disturbance effects. Therefore, particular attention has been drawn to nonlinear control strategies. At this time, just few papers this cost-effective solution to the LVRT issue.

Therefore, future researches should be focused on the development of DFIG robust nonlinear control strategies.

\section{REFERENCES}

[1] R. Passey, T. Spooner, I. MacGill, M. Watt and K. Syngellakis, "The potential impacts of grid-connected distributed generation and how to address them: A review of technical and non-technical factors," Energy Policy, vol. 39, n¹0, pp. 6280-6290, October 2011.

[2] FERC, "Interconnection for wind energy," Docket N RM05-4-000 Order $\mathrm{N}^{\circ} 661$, USA, June 2005.

[3] FERC, "Interconnection for wind energy," Docket NRM05-4-001; Order $\mathrm{N}^{\circ} 661-\mathrm{A}$, USA, December 2005.

[4] E.On Netz GmbH, Bayreuth, Grid Code, High- and Extra-High Voltage, April 2006, available at http://www.eon-netz.com/.

[5] Ireland National Grid, Grid Code Version 2, "Wind farm power station grid code provisions, WFPS1,” pp.213-216, January 2007.

[6] X. Yingcheng and T. Nengling, "Review of contribution to frequency control through variable speed wind turbine," Renewable Energy, vol. $36, n^{\circ} 6$, pp 1671-1677, June 2011.

[7] M. Liserre, R. Cardenas, M. Molinas and J. Rodriguez, "Overview of multi-MW wind turbines and wind parks," IEEE Trans. Industrial Electronics, vol. 58, n4, pp. 1081-1095, April 2011.

[8] H.T. Jadhav and R. Roy, "A comprehensive review on the grid integration of doubly fed induction generator," International Journal of Electrical Power \& Energy Systems, vol. 49, pp. 8-18, July 2013.

[9] M. Tsili and S. Papathanassiou, "A review of grid code technical requirements for wind farms," IET Renewable Power Generation, vol. 3, n³, pp. 308-332, September 2009.

[10] B. Singh and S.N. Singh, "Wind power interconnection into the power system: A review of grid code requirements," The Electricity Journal, vol. $22, n^{\circ} 5$, pp. 54-63, 2009.

[11] B. Singh, S.N. Singh and L. Wang, Electric grid connection and system operational aspect of wind power generation, in Wind Energy Conversion System: Technology and Trends, S.M. Muyeen, (Eds.), Springer-Verlag: UK 2012.

[12] M. Mohseni and S.M. Islam, "Review of international grid codes for wind power integration: Diversity, technology and a case for global standard," Renewable and Sustainable Energy Reviews, vol.16, n6, pp. 3876-3890, August 2012.

[13] F. Iov, A. D. Hansen, P. Sørensen and N. A. Cutululis, "Mapping of grid faults and grid codes," Tech. Rep. Risø-R-1617(EN), Risø Nat. Lab., Tech. Univ. Denmark, Roskilde, Denmark, Jul. 2007.

[14] G.D. Marques and D.M. Sousa, "Understanding the doubly fed induction generator during voltage dips," IEEE. Trans. Energy Conversion, vol. 27, n², pp. 421-431, June 2012.

[15] Y. Ling and X. Cai, "Rotor current dynamics of doubly fed induction generators during grid voltage dip and rise," International Journal of Electrical Power \& Energy Systems, vol. 44, n¹, pp. 17-24, January 2013.

[16] P. da Costa, H. Pinheiro, T. Degner and G. Arnold, "Robust controller for DFIGs of grid-connected wind turbines," IEEE Trans. Industrial Electronics, vol. 58, n9, pp. 4023-4038, September 2011.

[17] M.J. Hossain, H.R. Pota, V.A. Ugrinovskii and R.A. Ramos, "Simultaneous STATCOM and pitch angle control for improved LVRT capability of fixed-speed wind turbines," IEEE. Trans. Sustainable Energy, vol. 1, n³, pp. 142-151, October 2010. 
[18] M. Rahimi and M. Parniani, "Efficient control scheme of wind turbines with doubly fed induction generators for low-voltage ride-through capability enhancement," IET Renewable Power Generation, vol. 4, n³, pp. 242-252, 2010.

[19] F.K.A. Lima, A. Luna, P. Rodriguez, E.H. Watanabe and F. Blaabjerg, "Rotor voltage dynamics in the doubly fed induction generator during grid faults," IEEE Trans. Power Electronics, vol. 25, n¹, pp. 118-130, January 2010.

[20] K.E. Okedu, S.M. Muyeen, R. Takahashi and J. Tamura, "Wind farms fault ride through using DFIG with new protection scheme," IEEE Trans. Sustainable Energy, vol. 3, n³, pp. 242-254, April 2012.

[21] S.M. Muyeen, R. Takahashi, T. Murata, J. Tamura, M.H. Ali, Y. Matsumura, A. Kuwayama and T. Matsumoto, "Low voltage ride through capability enhancement of wind turbine generator system during network disturbance," IET Renewable Power Generation, vol. 3, n¹, pp. 65-74, 2009.

[22] F. Díaz-González, A. Sumper, O. Gomis-Bellmunt and R. VillafáfilaRobles, "A review of energy storage technologies for wind power applications," Renewable and Sustainable Energy Reviews, vol. 16, n4, pp. 2154-2171, May 2012.

[23] A.H.M.A. Rahim and E.P. Nowicki, "Supercapacitor energy storage system for fault ride-through of a DFIG wind generation system," Energy Conversion and Management, vol. 59, pp. 96-102, July 2012.

[24] M.J. Hossain, H.R. Pota, V.A. Ugrinovskii and R.A. Ramos, "Improved low-voltage-ride-through capability of fixed_speed wind turbines using decentralised control of STATCOM with energy storage system," IET Generation, Transmission \& Distribution, vol. 6, n8, pp. 719-730, 2012.

[25] C. Abbey and G. Joos, "Supercapacitor energy storage for wind energy applications," IEEE Trans. Industry Applications, vol. 43, n³, pp. 769776, May-June 2007.

[26] J. Liang; W. Qiao and R.G. Harley, "Feed-forward transient current control for low-voltage ride-through enhancement of DFIG wind turbines," IEEE. Trans. Energy Conversion, vol. 25, n³, pp. 836-843, September 2010.

[27] D. Ramirez, S. Martinez, F. Blazquez and C. Carrero, "Use of STATCOM in wind farms with fixed-speed generators for grid code compliance," Renewable Energy, vol. 37, n¹, pp. 202-212, January 2012.

[28] P.S. Flannery and G. Venkataramanan, "A fault tolerant doubly fed induction generator wind turbine using a parallel grid side rectifier and series grid side converter," IEEE Trans. Power Electronics, vol. 23, n’3, pp. 1126-1135, May 2008.
[29] L. Yang, Z. Xu, J. Ostergaard, Z.Y. Dong and K.P. Wong, "Advanced control strategy of DFIG wind turbines for power system fault ride through," IEEE. Trans. Power Systems, vol. 27, n², pp. 713-722, May 2012.

[30] A.E. Leon, J.M. Mauricio and J.A. Solsona, "Fault ride-through enhancement of DFIG-based wind generation considering unbalanced and distorted conditions," IEEE. Trans. Energy Conversion, vol. 27, n`3, pp. 775-783, September 2012.

[31] R. Cardenas, R. Pena, S. Alepuz and G. Asher, "Overview of control systems for the operation of DFIGs in wind energy applications," IEEE Trans. Industrial Electronics, vol. 60, n7, pp. 2776-2798, July 2013.

[32] T. Long, S. Shao, C.Y. Li, Chun-Yin, E. Abdi and R.A. McMahon, "Crowbarless fault ride-through of the brushless doubly fed induction generator in a wind turbine under symmetrical voltage dips," IEEE Trans. Industrial Electronics, vol. 60, nº 7, pp. 2833-2841, July 2013.

[33] M.J. Hossain, H.R. Pota and R.A. Ramos, "Robust STATCOM control for the stabilisation of fixed-speed wind turbines during low voltages," Renewable Energy, vol. 36, n¹1, pp. 2897-2905, November 2011.

[34] K.H. Kim, Y.C. Jeung, D.C. Lee and H.G. Kim, "LVRT scheme of PMSG wind power systems based on feedback linearization," IEEE. Trans. Power Electronics, vol. 27, n`5, pp. 2376-2384, May 2012.

[35] A.H.M.A. Rahim and E.P. Nowicki, "Performance of a grid-connected wind generation system with a robust susceptance controller," Electric Power Systems Research, vol.81, n², pp. 149-157, January 2011.

[36] M.E.H. Benbouzid, B. Beltran, M. Ezzat and S. Breton, "DFIG driven wind turbine grid fault-tolerance using high-order sliding mode control," International Review on Modelling and Simulations, vol. $6, \mathrm{n}^{\circ} 1, \mathrm{pp} .29$ 32, February 2013.

[37] B. Beltran, M.E.H. Benbouzid and T. Ahmed-Ali, "High-order sliding mode control of a DFIG-based wind turbine for power maximization and grid fault tolerance," in Proceedings of the 2009 IEEE IEMDC, Miami (USA), pp. 183-189, May 2009.

[38] D. Ramirez, S. Martinez, C. Carrero and C.A. Platero, "Improvements in the grid connection of renewable generators with full power converters," Renewable Energy, vol. 43, pp. 90-100, July 2012.

[39] P. Crossley and A. Beviz, "Smart energy systems: Transitioning renewables onto the grid," Renewable Energy Focus, vol. 11, n5, pp. 54-59, September-October 2010.

[40] http://www.elspec-ltd.com/

[41] http://www.amsc.com/

[42] http://www.zigor.com/

[43] http://www.w2ps.es/ 